\title{
Gut regulatory peptides and intestinal permeability in acute infantile gastroenteritis
}

University of Newcastle upon Tyne, Department of Child Health G R Lawson $R$ Nelson A Aynsley-Green

Department of Clinical Biochemistry M F Laker

Royal Postgraduate Medical School, London M A L Ghatei

S R Bloom

Correspondence to: Dr G R Lawson. Sunderland District General Hospital, Kayll Road, Sunderland SR4 7TP

Accepted 10 October 1991

\begin{abstract}
The plasma concentrations of seven gut regulatory peptides were measured in 11 infants suffering from acute gastroenteritis. Samples were taken at the time of the acute illness, upon reintroduction of feeding, and three months after recovery. These results were compared with controls. In the infants with diarrhoea, a massive increase in the fasting plasma mean (SEM) concentrations of enteroglucagon was found at the time of illness (1292 (312) $v 79$ (27) $\mathrm{pmol} / \mathrm{l}$ ), with concentrations of pancreatic glucagon, peptide tyrosine tyrosine, and motilin also being increased $(17.8(3.1) v 6.3(1.1) \mathrm{pmol} / \mathrm{l}, 114.6$ $(15 \cdot 2) v 37.0(11.0) \mathrm{pmol} / 1,217.6(44.1) v 98.5$ (18.3 $\mathrm{pmol} / \mathrm{l})$ respectively). The preprandial concentrations of motilin were found to be still increased at recovery $(183.9(35.4) \mathrm{pmol} / \mathrm{l})$, but the concentrations of the other three peptides had returned to normal values. No differences in plasma concentrations of vasoactive intestinal polypeptide, neurotensin, or pancreatic polypeptide were found. An increased intestinal permeability was demonstrated at the time of diarrhoea by the urinary ratio of lactulose to mannitol, suggesting simultaneous gut damage.
\end{abstract}

The effects of regulatory peptides may be relevant to the pathophysiology of gastroenteritis in infants.

The efficient utilisation of food depends upon the integration of several aspects of gastrointestinal function. Food has to be propelled through the gut in an orderly sequence; local trauma caused by the passage of food leads to a need for mucosal regeneration. At appropriate times, digestive secretions enter the gut lumen, and the absorption of the nutrients thereafter depends upon adequate blood flow. The integration of the secretion of metabolic hormones is necessary to ensure homoeostasis. There is now good evidence to suggest that the secretion of regulatory peptides and their effects on target tissues through endocrine, paracrine, and neurocrine mechanisms have key parts to play in regulating these facets of digestive physiology. Moreover, massive postnatal surges of peptides have been described in neonates and have been proposed to have an important influence on the early adaptation of the gut to enteral feeding..$^{1-3}$ By 9 months of age the magnitude of the release of the gut regulatory peptides in response to feeding has diminished substantially from that seen in the neonatal period. ${ }^{+}$

Gut diseases in adults cause characteristic changes in the profiles of gut regulatory peptides, reflecting the nature and location of the disease, and the responses to therapy and recovery. ${ }^{5}$ Acute infectious diarrhoea is a very common clinical condition, but although significant disturbances in the plasma concentrations of several of these peptides have been described in adults, ${ }^{6}$ no information is available from studies on infants with gastroenteritis.

This study investigated changes which occurred in the circulating concentrations of gut regulatory peptides in infantile gastroenteritis, in order to determine the endocrine response that the gut mounts to infection in early life. To ascertain whether these changes were related to an alteration in gut mucosal function, intestinal permeability studies were performed using lactulose and mannitol. Similar studies have been used to assess mucosal integrity in coeliac disease and Crohn's disease, ${ }^{7}$ and other diarrhoeal diseases including gastroenteritis, ${ }^{8-10}$ where a damaged mucosa leads to an increased permeability.

\section{Patients and methods}

Eleven infants aged less than 2 years of age (range 3-15 months; mean 6.7) with acute gastroenteritis were studied. All had been previously well and none had a history of gastrointestinal disease. None of the infants was breast fed. They had all required admission to hospital for acute diarrhoea, this being defined as a change in bowel habit with three or more watery stools in the 24 hours before admission. Other medical and surgical causes of diarrhoea were excluded. The infants received glucose electrolyte solution (GES) by mouth until their symptoms had resolved, whereupon full strength feeds were introduced. Informed consent to investigate the infants was obtained from their parents and the study was approved by the joint university and hospital ethical committee.

Blood samples $(2 \mathrm{ml})$ were taken through an intravenous cannula, being drawn at presentation and then at the time of initiation of refeeding, first just before starting to feed and then 60 minutes after the first milk feed. This always followed a feed of GES by at least three hours. Finally, a fasting sample was taken three months after recovery, between 6 am and 8.30 am immediately before the first morning feed and at least six hours after the previous feed. Stools were collected from all patients for bacteriological and virological investigation, including examination by electron microscopy. Blood was also drawn from 14 control infants of similar ages (range 2-22 months; mean 9.9) 
who were undergoing minor elective paediatric surgery. A preoperative fasting sample and one taken one hour after a postoperative milk feed were collected.

All blood samples were taken into chilled heparinised tubes containing 800 kallikreininactivating units of aprotinin (Trasylol), and the plasma was separated within 15 minutes of sampling and stored at $-20^{\circ} \mathrm{C}$ until assayed. Plasma concentrations of enteroglucagon, pancreatic glucagon, peptide tyrosine tyrosine, motilin, vasoactive intestinal polypeptide, neurotensin, and pancreatic polypeptide were measured by specific and sensitive radioimmunoassay as described previously. ${ }^{11-16}$ Intestinal permeability tests were performed using a dual marker, steady state method. ${ }^{17}$ Lactulose and mannitol were chosen as markers because both are present in some infant feeds, both resist hydrolysis by intestinal enzymes, and both are passively absorbed by different routes across the intestinal wall, lactulose by paracellular pathways, and mannitol transcellularly. Neither marker is metabolised after uptake, and both are excreted wholly and solely in the urine where recovery approaches $100 \% .^{18} 19$ When the two markers are combined in test feeds the effects on the results of variables such as rate of gastric emptying, intestinal transit, distribution within the body, and renal clearance, apply equally to both. Their urinary recovery is therefore a measure of passive intestinal permeability and thus of mucosal integrity.

After an initial urine sample had been taken on admission, infants received their fluid requirements with GES and then full strength, reconstituted granulated Cow and Gate Premium milk feeds containing a fixed ratio $(5: 1)$ of lactulose and mannitol. This was achieved by adding $5 \mathrm{ml}$ of an aqueous solution containing lactulose $(4 \mathrm{~g} / 100 \mathrm{ml})$ and mannitol $(0.8 \mathrm{~g} / 100$ $\mathrm{ml})$ to every $100 \mathrm{ml}$ of made up GES or milk feed. The reconstituted granulated feeds contained less than $1 \mathrm{mg} / 100 \mathrm{ml}$ of either marker while GES contained none whatsoever. The addition of the aqueous solution produced concentrations of $200 \mathrm{mg}$ lactulose and $40 \mathrm{mg}$ mannitol per $100 \mathrm{ml}$ of fluid. For comparison, ready to feed Cow and Gate Premium formula contains approximately $300 \mathrm{mg}$ of lactulose and $20 \mathrm{mg}$ of mannitol respectively (unpublished results). No adverse effects such as vomiting or alteration of bowel habit were seen with the use of these test feeds.

A steady state of marker input and output was achieved after 12 hours of test fluid intake, this being the day after admission in all but one infant who had intravenous fluids for 24 hours.

Table 1 Table of mean (SEM) concentrations of gut regulatory peptides against the time of sampling

\begin{tabular}{|c|c|c|c|c|}
\hline & $\begin{array}{l}\text { Enteroglucagon } \\
(\text { pmol/l) }\end{array}$ & $\begin{array}{l}\text { Pancreatic } \\
\text { glucagon } \\
\text { (pmol/l) }\end{array}$ & $\begin{array}{l}\text { Peptide } \\
\text { turosine tvrosine } \\
\text { (pmol/l) }\end{array}$ & $\begin{array}{l}\text { Motilin } \\
(\text { pmoll/l) }\end{array}$ \\
\hline $\begin{array}{l}\text { At presentation } \\
\text { Fasting } \\
\text { Postprandial } \\
\text { Recovered fasting } \\
\text { Control fasting } \\
\text { Control postprandial }\end{array}$ & $\begin{array}{c}740(144) \\
1292(312) \\
1319(386) \\
122(41) \\
79(27) \\
297(106)\end{array}$ & $\begin{array}{r}13.1(1.6) \\
17.8(3.1) \\
15.4(2.5) \\
5.8(1.0) \\
6.3(1.1) \\
7.2(1.4)\end{array}$ & $\begin{array}{l}108 \cdot 7(25 \cdot 7) \\
114 \cdot 6(15 \cdot 2) \\
121 \cdot 1(22 \cdot 1) \\
21 \cdot 7(7 \cdot 1) \\
37 \cdot 0(11 \cdot 0) \\
43.9(11 \cdot 1)\end{array}$ & $\begin{array}{l}217 \cdot 6(44 \cdot 1) \\
177 \cdot 2(45 \cdot 3) \\
101 \cdot 4(30 \cdot 9) \\
183 \cdot 9(35 \cdot 4) \\
98 \cdot 5(18 \cdot 3) \\
60 \cdot 3(10 \cdot 8)\end{array}$ \\
\hline
\end{tabular}

Thereafter a daily random urine sample of at least $2 \mathrm{ml}$ was obtained on each day of the admission. Urine samples were stored at $-20^{\circ} \mathrm{C}$ with $0.1 \mathrm{ml} 10 \%$ sodium merthiolate, and marker analysis was performed by gas-liquid chromatography. ${ }^{7}$ Before discharge from hospital, the baby's mother was shown how to add the solution to reconstituted feed and was then given a supply of granulated feed and the marker solution. Infants were given this special feed for 48 hours before being reviewed four weeks after discharge, at which time a final random urine sample was collected. Solids were excluded from the diet for this period of two days in case they contained varying amounts of lactulose and mannitol.

Intestinal permeability was expressed as a urinary lactulose:mannitol excretion ratio calculated from amounts of the two markers present in the urine samples. A normal ratio of less than 0.55 was taken from a previous study undertaken in the same laboratory. ${ }^{9}$

Statistical analysis was performed by the nonparametric Wilcoxon's rank sum test, but data are expressed as mean (SEM) for convenience.

\section{Results}

GUT REGULATORY PEPTIDES

At presentation there was a massive increase in enteroglucagon concentrations $(p<0.001$ against control fasting and recovered fasting values) which persisted until the time of refeeding; there was no postprandial increment at that time. By the time of recovery the concentrations had returned to the normal range for age (fig 1, table 1)

There was an increase in pancreatic glucagon at presentation ( $<<0.01$ against control fasting and recovered fasting concentrations) which was more pronounced $(p<0.001)$ when fasting values just before refeeding were compared with recovered fasting or control fasting values (fig 2).

Peptide tyrosine tyrosine was found in high

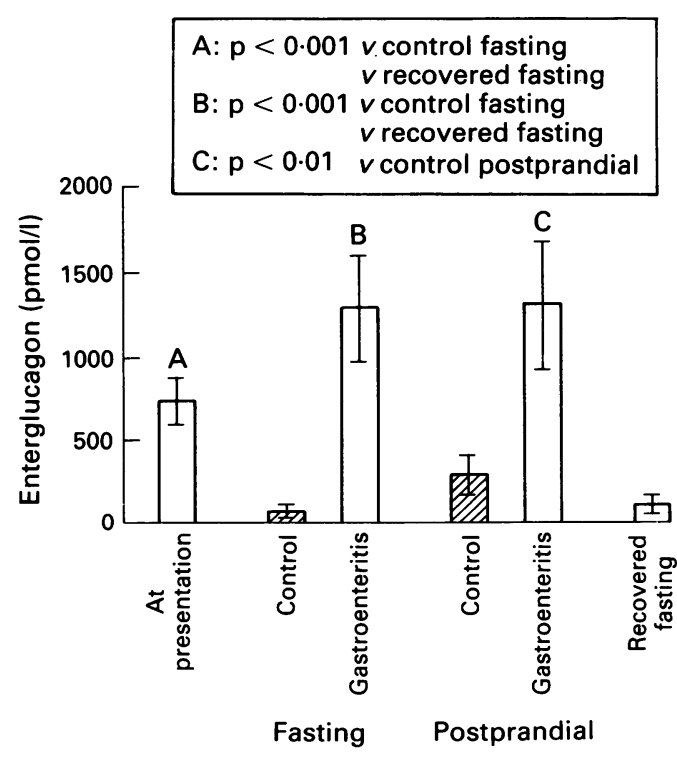

Figure 1 Mean (SEM) concentrations of enteroglucagon showing significant changes during and after gastroenteritis compared with control values. 


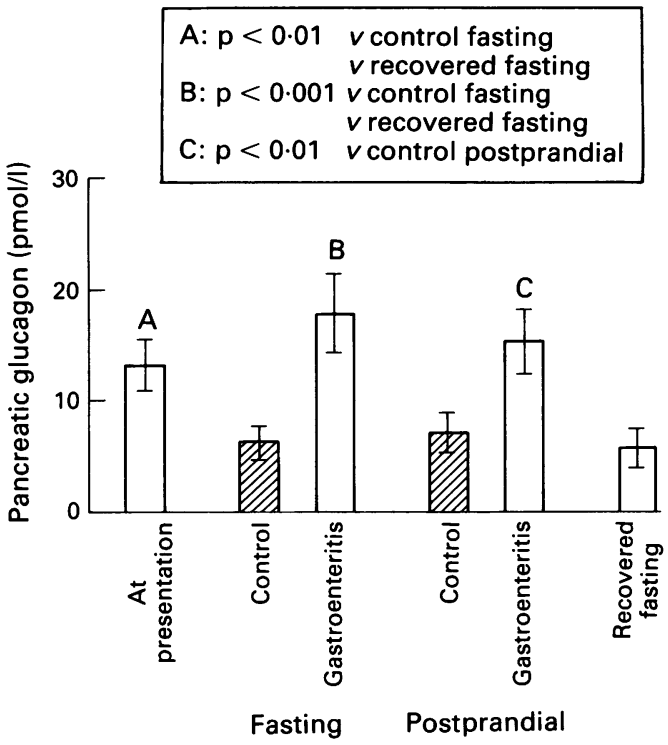

Figure 2 Mean (SEM) concentrations of pancreatic glucagon showing significant changes during and after gastroenteritis compared with control values.

concentrations at presentation and in postprandial samples $(p<0.01$ when compared with recovered fasting and postprandial control samples respectively). Fasting concentrations before refeeding were similarly increased (fig 3 ) $(\mathrm{p}<0.001$ when compared with control and recovered fasting values). There was no statistical difference between the latter two.

At presentation, concentrations of motilin were found to be greater than fasting $(p<0.02)$ and postprandial $(p<0.05)$ values in control infants. Moreover, the concentrations at recovery were still significantly high compared with control values $(p<0.05$ when compared with control fasting, and $\mathrm{p}<0.01$ when compared with control postprandial samples) (fig 4).

At no time were any significant differences
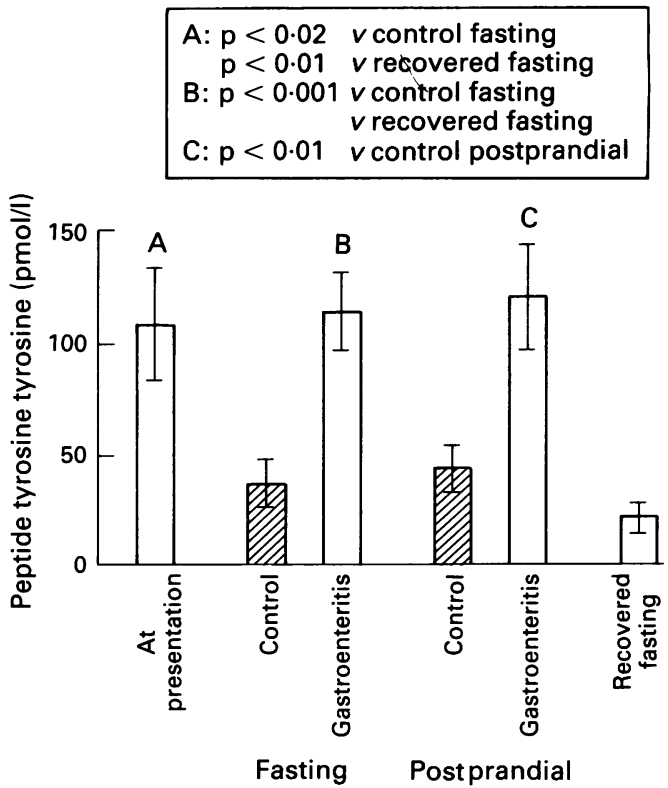

Figure 3 Mean (SEM) concentrations of peptide tyrosine tyrosine showing significant changes during and after gastroenteritis compared with control values. seen between control subjects and infants with gastroenteritis in the concentrations of vasoactive intestinal polypeptide, neurotensin, or pancreatic polypeptide.

\section{INTESTINAL PERMEABILITY}

The lactulose:mannitol ratio showed a significant increase on days $1(\mathrm{p}<0.01), 2$ and 3 $(p<0.05)$ but not on day 4 or thereafter, these results being compared with those at outpatient review (fig 5, table 2 ).

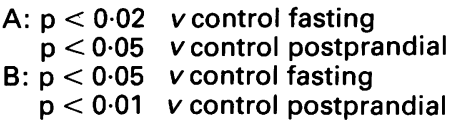

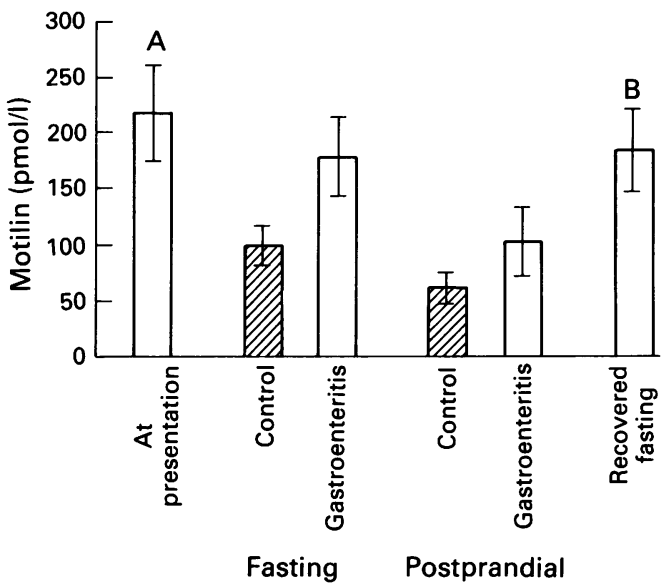

Figure 4 Mean (SEM) concentrations of motilin showing significant changes during and after gastroenteritis compared with control values.

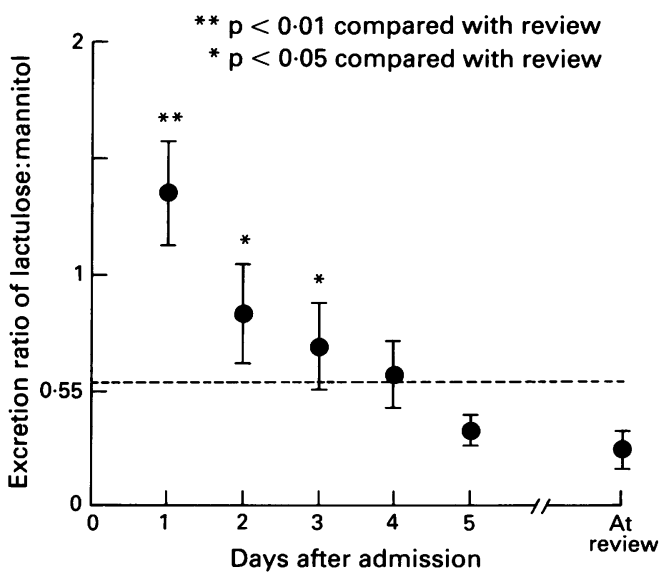

Figure 5 Excretion ratio of lactulose:mannitol in infants with acute gastroenteritis, expressed as mean (SEM).

Table 2 Table of lactulose:mannitol ratio against day of sampling, expressed as mean (SEM)

\begin{tabular}{ll}
\hline Day & Lactulose:mannitol ratio \\
\hline 1 & $1 \cdot 35(0 \cdot 22)$ \\
2 & $0.83(0 \cdot 21)$ \\
3 & $0.69(0 \cdot 18)$ \\
4 & $0.57(0 \cdot 14)$ \\
5 & $0.33(0 \cdot 06)$ \\
At review & $0.25(0.07)$ \\
\hline
\end{tabular}




\section{CLINICAL FEATURES}

Infants had one to seven days of diarrhoea before admission (average 3.6) which continued for one to five days (average $2 \cdot 1$ days) after admission and treatment with GES. These latter figures excluded two infants with prolonged diarrhoea (see below). Stool reducing substances were never more than $0.25 \%$ in the studied infants and only one child had symptoms (of persistent vomiting) which necessitated intravenous fluids for 24 hours.

\section{MICROBIOLOGY}

Virological and bacteriological analyses of the stools revealed that six of the 11 infants had single pathogenic stool viruses, five with rotavirus and one with adenovirus. Two infants with adenovirus had a second infective organism which was isolated, one having rotavirus and the other enteropathogenic Escherichia coli type 0 124. No causative organism was isolated from the stool in three infants.

\section{CHRONIC DIARRHOEA}

Two infants in our study went on to have more prolonged diarrhoea which lasted for seven weeks and four weeks respectively. The first of these infants had an adenovirus and $E$ coli type 0124 isolated from the stools, and had particularly high values for fasting and postprandial plasma enteroglucagon (2472 and $3106 \mathrm{pmol} / \mathrm{l})$, pancreatic glucagon (38 and $24 \mathrm{pmol} / \mathrm{l}$ ) and peptide tyrosine tyrosine (173 and $190 \mathrm{pmol} / \mathrm{l})$. After recovery the enteroglucagon concentration was $201 \mathrm{pmol} / \mathrm{l}$ which was well above the mean value, while the pancreatic glucagon and peptide tyrosine tyrosine had returned to normal values. The second infant with prolonged diarrhoea had rotavirus in stool samples but showed only one high value, that for fasting concentration of enteroglucagon, $1671 \mathrm{pmol} / \mathrm{l}$, taken at the begining of his illness.

\section{Discussion}

The most dramatic finding from this study was the massive increase in concentration of enteroglucagon at the time of acute gastroenteritis. Enteroglucagon is found mainly in the ileum and colon. Raised circulating concentrations have been found in starved and refed rats, ${ }^{20}$ in acute diarrhoea in adults, ${ }^{6}$ as well as in patients with coeliac disease ${ }^{21}$ and after ileal resection. ${ }^{22}$ It is a hormone which is thought to stimulate mucosal growth and to slow down gastrointestinal transit, ${ }^{23}$ and changes in its plasma concentrations are particularly impressive in the postnatal period when the normal neonate adapts to enteral nutrition. ${ }^{24}$ Although it is difficult to extrapolate directly to the previous studies performed in adults with diarrhoea because of interassay variation in the measurement of these peptides performed in the same laboratory, when the mean concentrations in adults are compared with infants with diarrhoea, the concentrations in infants are some 15-fold higher. This may be due to a decreased plasma clearance mechanism for the hormone at this age, but it is more likely to be due to a gut endocrine system in babies which is more responsive to insults at a time of rapid growth and development of the gastrointestinal tract. Two infants in our study went on to have more prolonged diarrhoea, and both had particularly high concentrations when they first presented, but neither had unusually high permeability ratios. Thus the magnitude of enteroglucagon rise in diarrhoea may be related more closely to the extent of mucosal repair rather than to its actual damage.

In addition to the above hypotheses, it is known that viral enteritis causes mucosal damage particularly in the jejunum, while enteroglucagon is found in highest concentrations in the terminal ileum. The increase in enteroglucagon may thus be a compensatory mechanism to allow an increased uptake of nutrients which have not been absorbed in the damaged proximal gut.

Pancreatic glucagon is a stress hormone which has powerful effects on hepatic metabolism, but may also have secondary effects on gut motility and on gut growth. Although blood glucose concentrations were not measured in our study, hyperglycaemia is a well documented feature in acute gastroenteritis in infants. ${ }^{25}$ This may well be related to the increased concentrations of pancreatic glucagon which were detected in our study, but not in the similar study in adults. The above findings may be because babies may have a more labile entero-insular axis, or are more severely stressed by their illness, and thus produce glucagon as a stress hormone.

The third hormone to demonstrate a considerable change during the course of the illness was peptide tyrosine tyrosine. It is known from infusion studies in adult men that concentrations of peptide tyrosine tyrosine in the physiological range have potent inhibitory effects on gastric secretion and emptying, ${ }^{26}$ and also delay the mouth to caecum transit time. ${ }^{27}$ As there is a surge of peptide tyrosine tyrosine concentrations in the neonate in the first month after birth during which time there are marked changes in gut motility and acid secretion, it has been suggested that this peptide may play an important part in the adaptation of the neonate to enteral feeding. ${ }^{28}$ The apparently paradoxical increase of peptide tyrosine tyrosine in gastroenteritis may thus represent part of a feedback loop which would aid the eventual resolution of diarrhoea in infants with gastroenteritis. However, it is also known that plasma concentrations of peptide tyrosine tyrosine correlate quite well with intestinal cell proliferation after dietary manipulations in the animal model, and correlate very well with plasma enteroglucagon concentrations. ${ }^{29}$

The other hormone to show significant changes in concentrations during the illness was motilin, a peptide which is associated with the contraction of the gut. ${ }^{30}$ It was the only hormone whose plasma values had not returned to normal concentrations three months after clinical recovery had occurred. None of the infants had experienced recent diarrhoea or had been symptomatic with intestinal motility 
problems including colic. These results may be related to the different degrees and type of fasting which the infants experienced when samples were taken during illness and then in recovery. However, the data could suggest that gastroenteritis in infants has a persisting effect on the secretion of this hormone, and further work is needed to determine the natural history and physiological consequences of these observations.

An enhanced intestinal permeability ratio confirmed that acute mucosal damage had occurred, this resolving in the days after admission. At review the ratio was always less than 0.55 . The high ratio was in keeping with previously reported studies of gastroenteritis which have suggested that a loss of mucosal integrity and decreased mucosal surface area may explain these results. ${ }^{89}$ Mucosal damage was demonstrated at the same time as the acute diarrhoee and the changes in circulating concentrations of enteroglucagon, pancreatic glucagon, peptide tyrosine tyrosine. Resolution of the increased intestinal permeability had occurred by one month, and of these gut regulatory peptides by three months, both being at times when no gastrointestinal symptoms were reported. Thus an association between acute gastroenteritis and mucosal damage with an alteration in gut regulatory peptides has been established.

The functional importance of the findings of raised plasma concentrations of enteroglucagon, pancreatic glucagon, peptide tyrosine tyrosine, and motilin in infants with gastroenteritis has yet to be defined. Our data strongly suggest that the infant gut reacts differently to that of adults during gastroenteritis, with an exaggerated increase in enteroglucagon and a persistent increase in motilin. They also suggest that plasma concentrations of gut regulatory peptides may act as markers of gut recovery. Further study is therefore needed in those children who develop chronic diarrhoea, particularly those with malnutrition, in whom the measurement of gut regulatory peptides might also be used to determine the effectiveness of treatment.

We thank Newcastle Area Health Authority who supported Dr G R Lawson as a Research Fellow, and Cow and Gate Ltd who supplied the granulated milk.

1 Lucas A, Bloom SR, Aynsley-Green A. The development of gut hormone responses to feeding in neonates. Arch Dis Child 1980;55:678-82.

2 Lucas A, Bloom SR, Aynsley-Green A. Postnatal surges in plasma gut hormones in term and pre-term infants. Biol Neonate 1982;41:63-7.

3 Lucas A, Aynsley-Green A, Bloom SR. Gut hormones and the first meals. Clin Sci 1981;60:349-53.

4 Salmanpera L, Perheentupa J, Sümes MA, Adrian TE, Bloom SR, Aynsley-Green A. Effects of feeding regimen on blood glucose levels and plasma concentrations of pancreatic hormones and gut regulatory peptides at nine months of age: comparison between infants fed with milk formula and infants exclusively breast fed from birth. I Pediatr Gastroenterol Nutr 1988;7:651-6.

5 Bloom SR, Polak JM. Plasma hormone concentrations in gastro-intestinal disease. In: Crutzfeldt $\mathrm{W}$, ed. C.linics in gastro-intestinal disease. In: Crutzfeldt W, ed. C.imics
gastroenterologv. London: Saunders, 1980:9:785-98.

6 Besterman HS, Christofides ND, Welsby PD, Adrian TE, Sarson DL, Bloom SR. Gut hormones in acute diarrhoea. Sarson DL, Bloom SR.

7 Pearson ADJ, Eastham EJ, Laker MF, Craft AW, Nelson R. Intestinal permeability in children with Crohn's disease and coeliac disease. $B M F$ 1982;285:20-1.

8 Ford RPK, Menzies IS, Phillips AD, Walker-Smith JAB, Turner MW. Intestinal sugar permeability: relationship to diarrhoeal disease and small bowel morphology. I Pediatr Gastroenterol Nutr 1985;4:568-74.

9 Weaver LT, Chapman PD, Madeley CR, Laker MF, Nelson $R$. Intestinal permeability changes and excretion of microorganisms in stools of infants with diarrhoea and vomiting. Arch Dis Child 1985;60:326-32.

10 Noone C, Menzies IS, Banatvala JE, Scopes JW. Intestinal permeability and lactose hydrolysis in human rotaviral gastroenteritis assessed simultaneously by non-invasive differential sugar permeation. Eur $\mathcal{J}$ Clin Invest 1986;16: differential

11 Ghatei MAL, Uttenthal LO, Christofides ND, Bryant MG, Bloom SR. Molecular forms of human enteroglucagon in tissue and plasma. F Clin Endocrinol Metab 1983;57: 488-95.

12 Adrian TE, Ferri GL, Bacarese-Hamilton AJ, Fuessl HS, Polak JM, Bloom SR. Human distribution and release of a putative new gut hormone, peptide YY (PYY). Gastroenterology 1985;89:1070-7.

13 Christofides ND, Bryant MG, Ghatei MA, et al. Molecular forms of motilin in the mammalian and human gut and human plasma. Gastroenterology 1981;80:292-300.

14 Mitchell SJ, Bloom SR. Measurement of fasting and postprandial plasma VIP in man. Gut 1978;19:1043.

5 Lee YC, Allen JM, Uttenthal LO, Roberts PM, Gill SS, Bloom SR. Quantitative analysis and characterisation of human plasma neurotensin-like immunoreactivity in response to a meal. Dig Dis Sci 1985;30:129-33.

16 Adrian TE, Bloom SR, Bryant MG, Polak JM, Heitz PH, Barnes AJ. Distribution and release of human pancreatic polypeptide. Gut 1976;17:940-4.

17 Weaver LT, Laker MF, Nelson R. Intestinal permeability in the newborn. Arch Dis Child 1984;59:236-41.

18 Laker MF, Menzies IS. Increase in human intestinal permeability following ingestion of hypertonic solutions. meability following ingestion

19 Laker MF, Bull HJ, Menzies IS. Evaluation of mannitol for use as a probe marker of gastrointestinal permeability in man. Eur $\mathcal{F}$ Clin Invest 1982;12:485-91.

20 Goodlad RA, Wright NA. Cell proliferation, plasma enteroglucagon and plasma gastrin levels in starved and refed rats. Virchows Arch [B] 1983;43:55-62.

21 Besterman HS, Bloom SR, Sarson DL. Gut hormone profile in coeliac disease. Lancet 1978; i:785-8.

22 Besterman HS, Adrian TE, Mallinson CN. Gut hormone release following intestinal resection. Gut 1982;23:854-61.

23 Bloom SR. An enteroglucagon tumour. Gut 1972;13:520-3.

24 Lucas A, Adrian TE, Christofides ND, Bloom SR, AynsleyGreen A. Plasma motilin, gastrin and enteroglucagon and feeding in the human newborn. Arch Dis Child 1980;55: 673-7.

25 Stephenson RE, Bowyer FP. Hyperglycaemia with hyperosmolarity; dehydration in non-diabetic infants. $\mathcal{F}$ Pediatr 1970;77:818.

26 Adrian TE, Savage AP, Sagor GR, et al. Effect of peptide YY on gastric pancreatic and biliary function in humans. Gastroenterologv 1985;89:494-9.

27 Savage AP, Adrian TE, Carolan G, Chatteriee VK, Bloom SR. Effects of peptide YY (PYY) on mouth to caecum intestinal transit time and on the rate of gastric emptying in healthy volunteers. Gut 1987;28:166-70.

28 Adrian TE, Smith HA, Calvert SA, Aynsley-Green A, Bloom SR. Elevated plasma peptide $Y Y$ in human neonates and infants. Pediatr Res 1986;20:1225-7.

29 Goodlad RA, Ienton W, Ghatei MA, Adrian TE, Bloom SR, Wright NA. Effects of an elemental diet, inert bulk and different types of dietary fibre on the response of the intestinal epithelium to refeeding in the rat and relationship to plasma gastrin, enteroglucagon and PYY concentrations. Gut 1987;28:171-80.

30 Vantrappen G, Janssens J, Peeters TL, Blood SR, Christofides ND, Hellemans $J$. Motilin and the interdigestive migrating complex in man. Dig Dis Sci 1979;24:497-500. 